\title{
'The confidence to do things that I know nothing about' - skills development through extra-curricular inquiry activity
}

\section{Jamie Wood}

University of Manchester, UK

\section{Sabine Little}

University of Sheffield, UK

\section{Louise Goldring}

Royal College of Surgeons, UK

\section{Laura Jenkins}

University of Sheffield, UK

\section{Abstract}

This article presents the findings of a survey given to students engaging in educational enhancement activities in inquiry/enquiry-based learning at two Centres for Excellence in Teaching and Learning (CETL). The students involved were asked to comment on the skills they felt that they had developed as part of their roles as 'interns' and 'ambassadors'. These comments were analysed inductively and several strong themes emerged. Students valued the opportunity to engage in such activities, which developed a wide range of transferable skills and had a positive impact on their academic work and their prospects for future employment. While there is a considerable amount of literature on higher education and skills development, a growing body of work on how curricular inquiry-based learning impacts upon students' capabilities, and a plethora of studies on how paid and unpaid extra-curricular activities affect students' educational achievement, few studies have sought to relate these areas of research.

Keywords: Skills Development; Students as Partners; Inquiry-Based Learning; Centres for Excellence 


\section{Introduction and background}

This article reports research into students' perceptions of the skills they had gained from engaging in educational development activities at two Centres for Excellence in Teaching and Learning (CETL) in inquiry-based learning. The article begins by introducing the institutional contexts in which the students worked before offering short literature reviews on the topics of transferable skills in higher education, skills development and inquirybased learning, and the relationship between extra-curricular activity, academic achievement and skills development. The next section outlines the methodology adopted, followed by the results, divided according to students' perceptions of their development of academic and transferable skills, and the students' views on the importance of these skills for future employability. The discussion section draws out the implications of the research and addresses additional points of interest, including: how the student activities and accompanying learning processes were facilitated; and what institutions can learn from adopting more formalised approaches to extra-curricular activity.

\section{The CETL context}

The Centre for Excellence in Enquiry-Based Learning (CEEBL) at the University of Manchester and the Centre for Inquiry-based Learning in the Arts and Social Sciences (CILASS) at the University of Sheffield were two Centres for Excellence in Teaching and Learning (CETLs), funded by the Higher Education Funding Council for England (HEFCE) from 2005 to 2010 in recognition of institutional excellence in inquiry-based learning. Both CETLs placed student engagement at the centre of their educational development initiatives. This included the formation of networks of students, the members of which were paid to engage in a range of activities to promote and support inquiry-based learning in their departments, across the institution and externally.

\section{A note on spelling}

Throughout the literature, reference is made to both enquiry-based learning (e.g. Khan and O'Rourke, 2004; Hutchings, 2007) and inquiry-based learning (e.g. Brew, 2003; Healy, 2005). Hutchings (2007) points out that the differences in spelling have historical and linguistic roots, and do not reflect inherently different interpretations of pedagogy. Given this difference and recognising that the two CETLs featured here took their names 
from enquiry- and inquiry-based learning, we have chosen to adopt the term inquiry-based learning (IBL) and therefore apply it consistently throughout this article.

\section{The Student Intern Programme at CEEBL}

Interns were current students at the University of Manchester recruited from a range of disciplines and degree levels. CEEBL employed new student interns each year and aimed to include at least one student from each of the four faculties that make up the university. The CEEBL Intern Programme developed out of The University of Manchester's Students as Partners model and as such offered staff the opportunity to work closely with students in the development, delivery, evaluation and dissemination of their InquiryBased Learning modules. Student interns were co-consultants, and worked one day per week alongside staff coordinators in their home Faculties. Interns also contributed to research and evaluation within CEEBL and were encouraged to focus on a specific interest or project during their internships. The interns also came together for larger events such as workshops or conferences. For the academic year 2008/09 the intern programme was expanded to include an Intern from the Manchester Business School and two extra interns to work across all the faculties in order to improve and foster interdisciplinary relationships. The intern programme was coordinated by a full-time sabbatical officer.

\section{The Student Ambassador Programme at CILASS}

CILASS student ambassadors were drawn from the student body of the University of Sheffield. Students worked directly with CILASS core staff, as well as departmental staff champions for inquiry-based learning, in order to feed the student perspective into IBLrelated curriculum enhancement.

Students worked across a total of 26 departments. Apart from two departments, who had two ambassadors each due to their size, each department had one student ambassador, resulting in a Student Ambassador Network of 29 at full capacity (including a student coordinator). Ambassadors worked for a total of 60 hours each over the academic year. The network was co-facilitated by one member of staff and one full-time student, who worked for CILASS for 135 hours over the academic year. As well as helping to manage day-to-day activity of the network, each student co-coordinator was encouraged to identify an area of interest to research and disseminate during their time in post. The 
network operated at three levels: with ambassadors working individually in their departments; as a full network on a number of large events (e.g. an annual student conference on IBL); and in five working groups focusing on producing a student journal, evaluating CILASS projects from the student perspective, dissemination, multimedia productions (e.g. films), and support for CILASS technologies. As well as being paid for the work they did, CILASS student ambassadors had the option to use their work to gain credit towards the Sheffield Graduate Award, established in 2006/07, which focuses on skills development in relation to the institution's vision of the Sheffield Graduate (The University of Sheffield, n.d.; see e.g. Atlay and Harris (2000) for a similar programme at Luton University; and Muldoon (2008) for a model in Australia).

\section{Comparison of the networks}

The networks therefore shared a range of characteristics, which bear brief repetition. Both student ambassadors (at CILASS) and interns (at CEEBL) worked with academic staff on educational/curriculum development projects. They also worked with members of the 'core' teams at each CETL to take forward strategic priorities for the CETL. The approach taken by the staff members with whom the students engaged was largely facilitative and based on a partnership in which students were trusted to work independently on agreed tasks, and where collaboration between staff and students might have been initiated by either party. Describing such partnership from the research context, Kirshner et al. (2005, p.136) note that:

When youth are involved as full research partners, they are more likely to have transformative developmental experiences as they are more engaged in defining and coming to understand research problems, questions and findings, are placed in positions of greater responsibility, and have more participatory and nonhierarchical interactions with adults.

The way in which the student ambassadors and interns worked, whether in groups or individually, was often inquiry-based - i.e. students were given a task but a relatively large degree of freedom in determining how to take it forward to completion. In practical terms, it was also important to note that students in both networks were paid on a part-time basis, while in contextual terms, the universities of Manchester and Sheffield are of a comparable standing: both are red brick, research intensive institutions in the north of England. 
One conceivable difference between the networks is the students' level of study - whereas the majority of student ambassadors at CILASS are undergraduate students, within the CEEBL intern body there is more of a balance between undergraduate, taught postgraduate and PhD students.

\section{Literature review}

In recent years there has been a steady increase in research and publication on the impact of both extra-curricular activities and inquiry-based learning on students' skills development. This research can be divided into the following categories which, for reasons of space, are summarised more fully elsewhere (Wood et al., 2011).

1. Transferable skills in higher education.

2. Skills development and inquiry-based learning.

3. Extra-curricular activity, academic achievement and skills development.

In general, studies have reported a positive correlation between skills development and inquiry and extra-curricular activities, although much of the research is based on analysis of individual cases rather than synthetic surveys.

\section{Methods and methodology}

It should be remembered when interpreting the data that were collected during this study that none of the students who responded had already been active in the full-time postuniversity job market. Data were therefore gathered in front of a background of perceived development needs, an approach to evaluating students' skills development which has been used at the University of Lancaster by Nabi and Bagley (1998), and which produced valuable, though inconclusive, results. Curtis and Shani (2002) likewise have examined students' perceptions of the impact of paid work on their academic studies, discovering that students in paid employment felt that it had a positive effect upon their confidence, interpersonal, time management and communication skills, and in some cases helped them to relate what they had learnt in class to the world of work. There thus seems to be 
a developing interest in analysis of student perceptions of the relationship between paid employment and the development of disciplinary and other skills.

Schamber (2000) points out the need for inductive analysis in order to avoid a priori structuring and bias towards the data. The advantage of this approach is that it allows the researcher to form questions, hypotheses and theories during the course of the research process. In the case of the research reported in this article, such a responsive methodology was useful because some of the data on which the research drew had already been collected as part of the process of evaluating CETL-supported activities. The combination of inductive analysis of reports and additional data gathered via questionnaires makes it possible to combine both pre-conceived, unprompted perceptions and reflective data following targeted questioning. Through an integrated process of data collection and analysis, sometimes referred to as triangulation (though the use of this terminology has recently come under increased scrutiny (Moran-Ellis et al., 2006)), we sought to achieve a richer picture of the topic than would be possible through a singlemethod approach (Cohen et al., 2000; Mathison, 1988).

As part of the standard evaluation of the impact of the CEEBL intern and the CILASS ambassador networks, data were gathered from students every year. In recognition of the lack of research into the links between extra-curricular IBL, skills development and academic achievement, and of the ambiguous nature of much existing research, it was decided to conduct a more in-depth investigation into student perceptions of these issues. The similarities between the networks, the institutions from which they came, and the almost identical thematic foci of their respective CETLs meant that we could draw on a deeper body of experience and evidence than would otherwise have been possible. This was especially important given the lack of existing literature on the topic. The study adopted a qualitative, multi-method approach, combining the collection of original evaluative data and the consultation of pre-existing reflective material in order to gain the best possible insight into students' perceptions. Data presented here were largely gathered via a qualitative survey given to CILASS student ambassadors during a network meeting. Seventeen responses were received, a 100\% response rate based on attendance at the meeting. These data were augmented with nine interim and final reflective reports completed by CEEBL student interns as part of their post, and further by reflective reports completed by CILASS student ambassadors who used their work in order to gain the Sheffield Graduate Award, a skills-based additional qualification available for 
students at the University of Sheffield (The University of Sheffield, n.d.). This method of data collection allowed for direct responses to pertinent pre-defined questions, at the same time as facilitating the emergence of themes identified as important by the students themselves. The following questions were used:

1. What have you enjoyed about being a Student Ambassador?

2. What three skills do you feel you have gained/developed by being a Student Ambassador?

3. How has it impacted on your wider university career?

4. What impact do you think it will have on your life after university?

At CEEBL, student interns were required to write self-reflective reports at the mid- and end-point of their internship. The reports took the form of a piece of reflective writing, which were generally at least one page of A4 paper, but in some cases significantly longer (up to 4 pages). At the time of research (while the CETLs were still operational) we obtained permission from nine past interns to analyse their reports using the questions above. Current (at the time the research was conducted) CEEBL interns were also asked to write a short paragraph on what they felt they had gained from their internship, which included reflection upon the skills they had developed. The questionnaires and reports were analysed inductively in order to identify common themes. These themes form the basis of our analysis.

\section{Results}

At the most general level, students reported that they enjoyed being members of the ambassador and intern networks. The development of social relationships tallies with the research into the impact of involvement in college governance upon student engagement (Astin, 1999; see also Eccles et al., 2003; Curtis and Shani, 2002). The cross disciplinary nature of the networks was also noted as a positive factor by the students, as was the opportunity to interact with students from other year groups and staff from across the university, for example: 
I have enjoyed meeting people from different departments and discussing what goes on in their departments. You can't help but feel isolated from other departments, which is to be expected, but learning about the experiences of different departments is good.

The sense of belonging in relation to the institution via engagement with extra-curricular activities, suggested by Bringle and Hatcher (1996) and Eccles et al. (2003), certainly seems to be borne out by the students' experiences. Connected to this, students commented positively on the opportunity to contribute to shaping their courses: 'I am proud of my achievement of setting up EBL within my own course, as most of the past curricula have involved lectures or practicals, so this is a new development'.

Given the comparative nature of the project it is worth noting here that there were no significant differences between the students from the two networks in terms of their perceptions of skills development. Very similar themes could be picked out in the response of students from both networks. This similarity is striking given the different contexts of the two networks and the varying data collection methods which were employed: CILASS took a more quantitative approach and CEEBL a more qualitative approach. The congruity between responses at the two institutions is interesting and suggests that the commonalities between the strategies adopted (e.g. payment of students, inquiry- and team-based approach to working, facilitation from CETL staff) in the networks had similar outcomes in terms of skills development.

\section{Academic skills}

Eccles et al. (2003) note that there is an increasing volume of evidence for a positive correlation between extra curricular activity and students' academic development: several different studies suggest that involvement in constructive, non-academic activities both at school and in the community facilitates continued school engagement and academic achievement (Eccles et al. 2003, p. 883). Bringle and Hatcher (1996) also note the positive interrelationship between 'service learning' and academic achievement and engagement, in which 'service learning' is a:

...course-based, credit-bearing educational experience in which students (a) participate in an organized service activity that meets identified community needs, 
and (b) reflect on the service activity in such a way as to gain further understanding of course content, a broader appreciation for the discipline, and an enhanced sense of civic responsibility. (Bringle and Hatcher, 2000, p. 274)

There are three main themes through which this trend is manifested and ultimately confirmed by our data: students gaining greater practical knowledge about how the institution works; students gaining a range of skills that are directly relevant to their academic studies; and students developing a deeper awareness of the learning process.

As noted above, a number of students seem to have developed a greater sense of connection with the university through their active participation in teaching and learning initiatives. A side effect of such a development is that they also gained significant insights into how the institution is structured and functions operationally, for example, 'I got to know my lecturers better, the library structure, and people who can help me'. This has obvious benefits for the students concerned and is clearly a positive outcome, but must raise questions about the accessibility and dissemination of information through institutional support mechanisms more broadly, since it should not be necessary for the students to join extra-curricular networks in order to gain access to this sort of information.

Virtually every student described themselves as having developed some academic or academic-related skills in the course of their ambassador/intern roles. Again, this corresponds with the findings of much of the literature on the relationship between extracurricular activities and academic achievement. Although there is no obvious dividing-line between transferable and academic skills, the following evidence is more closely related to academic activity than the more generic skills outlined previously. As the students from both networks engaged in evaluation and research activities, such as running and writing up focus groups and authoring research and conference papers and presentations, they developed a range of evaluation and research skills that were reusable in the context of their disciplinary studies, for example:

The way in which I research material has improved; I cover a lot more ground whilst researching now, as my interest in this field has grown since becoming involved with CILASS. The importance of research and the technologies available to carry it out successfully were two key things CILASS has taught me. I tend to branch off from the typical route whilst writing my essays now, researching a subject 
thoroughly helps me to focus on the aspects of an assignment that really interest me rather than following the set route. I have definitely noticed an improvement in my grades due to this, as well as a higher degree of satisfaction with my study. Students felt that they had developed a suite of skills that related to the entirety of the research process, starting with improved creativity in coming up with new ideas, data collection through evaluation methodologies, analytical skills in examining that information, and finally, writing skills in compiling reports or documents for dissemination. In terms of writing skills, there was a recognition that the diversity of activities in which the networks are engaged offered opportunities for developing the ability to write in a range of registers: research articles, practical pedagogical guides, student journal articles and newsletter articles were all referred to as writing styles which students had to master. It is also important to note that several respondents emphasised specifically that they had developed the ability to use these skills in collaboration with their fellow students.

A number of students appear to have derived significant cognitive benefits from their roles as interns and ambassadors. They increased their awareness of IBL as a pedagogic approach and of the process of learning in general: 'Being the student ambassador [...] has been an enlightening experience in terms of learning about processes of IBL learning, particularly within my own department'. This is hardly surprising as the students carry out their activities using an inquiry-based approach and are frequently involved as partners and/or consultants in educational development initiatives. One student reported a broadening of their understanding of the concept of university: '[The network] helped me to understand that uni isn't just about lectures'. This echoes Schraw et al.'s (2006) previous research into IBL and other more active forms of learning, which suggested that such pedagogies have advantages over transmission forms of teaching in terms of developing students' abilities to self-regulate, as well as their meta-cognitive capabilities.

\section{Transferable skills}

Much of the introductory literature on IBL refers to students developing a range of generic skills through engagement in inquiry activities (e.g. Kahn and O'Rourke, 2004) and this appears to be borne out by the student responses. Students identified a range of skills they had developed as part of their engagement in the CETLs. Working at a variety of levels (i.e. as individuals, in small groups, and as a large unit) assisted them in 
appreciating the various skills involved at each level. The following skills were cited almost unanimously by all students working with both CETLS:

- Interpersonal skills, including: communication, confidence, listening, networking.

- Team-working skills, including: group work, collaboration, learning from others.

- Presentation skills.

- Reflective skills.

- Self-direction, including: organisation, time management, working to deadlines, decision making.

- Project management skills, including: event planning, running events/training, producing resources.

These findings tally with those of Curtis and Shani (2002) on the impact of paid work on student capabilities, who emphasised the development of greater self confidence as the most significant positive effect of paid employment (see also Gilman et al. (2003) on structured extra-curricular activities). Depending upon the specific types of work in which the students had been engaged and the training they had received, more specific and technical skills had also been developed. These included, but were not confined to: filming, specific IT skills, skills in facilitating focus groups, leadership, teaching and facilitation skills. The following quotation is emblematic: '[My experience] will provide me with the confidence to do things that I know nothing about; which is exactly how I started off with CILASS'.

\section{Importance for employability}

Students were very much aware of the transferability of these skills and explicitly linked their work with the CETL to future career paths. This included statements such as 'if I choose an academic career, I will have a better understanding of teaching and learning processes'. In addition to asking the students about their perceptions of the skills they were gaining at university and in their extra-curricular activities, they were also questioned about what impact they felt this would have on their future employability and careers. All students were in agreement that the experience of engagement in these networks had improved their employment prospects. Their feelings are well summarised by the following comment: 
A lot of people have got degrees, and employers are finding it increasingly difficult to distinguish between prospective candidates - 'okay, you've got a degree, but what does that mean to our organisation?'

Beyond the general observation that experience of extra-curricular work would serve to distinguish students from their peers there were three different classes of comments. Firstly, from a relatively pragmatic perspective, students recognised that working as ambassadors or interns had prepared them to deal with questions at interview or provide examples on application forms. Secondly, some students made broader observations about how the experience helped them to differentiate themselves from other candidates through the development of inquiry-related capabilities. For example:

I will be more able to research confidently and productively, as well as being able to work successfully within a team (prior to CILASS any study/assignments I had done were independent). These are both valuable skills in the workplace and will hopefully be received well in interviews/job applications in the future.

Thirdly, respondents described the development of particular skills which might help them target specific careers. For instance:

I have also been considering going into teaching after finishing my degree which is a career that is centred on IBL; my heightened understanding of IBL would surely be a valuable asset in the teaching profession.

I have applied for the Trainee Scheme in Programme Production with the BBC something which, had I not been part of the Film Group, I would not have felt I could have applied for.

Overall, therefore, the student members of the ambassador and intern networks considered themselves to have developed a significant range of academic and generic skills which they felt would be of value in both applying for jobs and in their future careers. 


\section{Discussion}

The students' comments mirror findings from the literature on curricular IBL and skills development, including those from the Sciences (Powell et al., 2007). In fact, were all the data the result of a specific IBL module, there might be little point in writing this paper. However, as the students perceived that these skills were developed through their engagement in extra-curricular activities, the question remains how these learning processes were facilitated, and what institutions might learn from the formalisation of extra-curricular activity. It is also striking how the skills which students perceive as having developed match almost exactly those outlined as highly desirable or essential by employers (Bennett, 2002) and governments in a series of reports throughout the 1990s (see Davies (2000) for a summary), rendering the question even more relevant.

How, then, are curricular and extra-curricular IBL opportunities related to one another? It is profitable to see these two modes of IBL as very similar in nature, even if the contexts are different ('education' as opposed to 'employment'). In curricular IBL the overall inquiries or problems are defined by the tutor and the students may be given varying degrees of freedom in further defining the exact issues that they will address and the process that they will go through in addressing them. Often this will vary according to the level of the student and/or their prior expertise, with more experienced students being given greater freedom to establish their own inquiries and to decide how they will approach them. This is very similar to the approach that the CETL student networks adopted. The students were often confronted with a task by the CETL organisation and were asked to address the task in an open way in dialogue with the network facilitator. Students with greater experience and expertise were given more freedom in addressing such tasks, as in curricular IBL. Of course, as in curricular IBL, on some occasions it was necessary to predetermine what the students would be doing in order to meet specific operational objectives, but the principle was to open out inquiries and activities wherever possible and thus to increase learning. Extra-curricular IBL thus closely models the processes of curricular IBL and faces the same constraints of pre-determined aims and objectives, as well as the need to support less experienced students in undertaking their inquiries.

It seems likely that the adoption of an inquiry-based approach to working in the networks was at least partly responsible for the development of skills by the interns and ambassadors, especially as these skills were very similar to those which curricular IBL has 
been shown to develop by previous research (Wood et al., 2011)). Students commented favourably on the freedom they had when working in groups in order to identify the approaches that were most suited to their task - whether this task was to produce a film, to present at a workshop, or to write a resource for other students. This corresponds to wider research on the positive impact of peer-group association on educational achievement (Feldman and Matjasko, 2005; Gilman et al., 2003). Despite this freedom, however, decisions needed to be discussed and negotiated. Being, essentially, employees of the respective CETLs, both networks had the remit to operate within clear pedagogical and strategic guidelines. This led to a constant negotiation process, asking that students compare their intended outcomes to that of the overall CETL. Staff guidance and facilitation, as well as peer feedback via the other students, led to a process of ongoing reflection, which enabled students to retrace the skills acquired through the process. As we did not ask students about skills they developed as part of their degree programme, we cannot make direct comparisons, however, the evidence suggests that students found it easier to link their extra-curricular activities to future advantages in the job market, especially as a distinguishing factor separating them from others seeking employment. No student made mention of the Sheffield Graduate Award, a formalised University of Sheffield scheme that recognises student engagement in extra-curricular activities. However, several students had signed up to the scheme, indicating that they had at least some awareness of multiple options available to them to document and capitalise upon skills which they had developed. The reflective approach of the Graduate Award seeks to highlight skills developed in any context (both intra- and extra-curricular), thus differentiating it from other schemes (Atlay and Harris, 2000; Muldoon, 2008). Further research could help illuminate how staff and students could work together to help students transfer these skills between different areas of engagement.

Students are obviously aware of skills they feel they need for employment. However, in a rapidly changing environment, where the concept of 'skills for life' is becoming obsolete, activities such as a student network for IBL creates a multi-disciplinary, problem-solving team with the remit to work on learning and teaching development, and thus ultimately the freedom to influence higher education, thereby filling the gap in such provision identified by Froman (1999). Whereas the skills cited by students roughly fit the very comprehensive analysis produced by Bennett (2002), it is important to remember that virtually all of the literature that has been produced to date concerns itself with skills gained through structured study. Thus, further research is needed regarding the transferability of skills 
gained through extra-curricular activities: while students felt they would be able to use certain skills as part of their degree, this has not been investigated, and a long-term followup with students once they have entered employment would assist in identifying just how realistic students' assumptions about their required skills for employment were. A longerterm study, returning to the same students, would alleviate Cranmer's (2006) concerns about skewing research, providing a comparative base, whilst at the same time providing data regarding the perceived usefulness of skills development both within and outside the curriculum.

Both projects were 'meta IBL': the students were consciously using an IBL approach to develop IBL in their institution. It is likely that this had some impact on their awareness of the skills that they were developing because IBL has a strong reflective element and this is something that the network facilitators encouraged the students to do as part of their roles and to refer to when discussing IBL with other students and staff. It is hard to imagine this not 'rubbing off' when the students came to consider their own learning. It is therefore likely that students who were not using an IBL approach to their work would be less likely to reflect on and recognise the skills that they develop through their extra-curricular work, and this is one of the reasons why we advocate adopting the IBL approach to student extra-curricular work. Indeed, students from the CILASS network did some valuable work in this area, running inquiry-based sessions with students at the University of Sheffield and other institutions to help them to recognise the skills that had been developed during their degrees, with a particular focus on the skills that IBL had inculcated (see Wood et al. (2011) for a full description). Another possible approach would be to tie in reflection on the skills developed in extra-curricular work (both paid and voluntary) into students' PDP and career planning processes. In terms of curricular experiences, it would not be difficult to encourage reflection on the skills that students have learnt in the course of particular modules by including a few additional questions on module evaluation surveys. Neither of these proposals would necessarily need to be tied to IBL or to extra-curricular work experience, although it would be interesting to see if those students who had experienced inquiry-based ways of working were better able to reflect on and recognise the skills that they had developed.

A key feature of the functioning of both networks has been the provision of experienced staff to support and facilitate the student ambassadors and interns (Wood et al., 2011). The role of the facilitator is not to direct the students, but to help them to set their own 
goals, to negotiate between the priorities of the CETL as a whole and the interests and abilities of the student networks, and to act as a buffer between academic and educational development staff and students, ensuring that both are aware of their roles and responsibilities. The facilitation of the network has obvious resourcing implications, as does the need to pay for the students' time and (in some cases) expenses. The benefits to the students in terms of skills and knowledge development are substantial, but we suggest that the impact of the activities goes beyond the personal development of individual students. In professionalising the roles of ambassador and intern there are benefits for the organisation as a whole. Put simply, the students are likely to become more reliable, better motivated and take their roles more seriously. This allows them to take on the role of full partners in the educational development enterprise, providing unique insights and ideas. At CEEBL and CILASS this is reflected in students writing research and conference papers alongside staff, presenting at and organising staff-student conferences, and engaging in independent educational development projects in their departments (for more on the activities of the two networks see Wood et al., 2011). Investing in these networks does require resourcing, but we suggest that the benefits for the students and the institution are substantial.

\section{Conclusion}

Ways in which extra-curricular student networks linked to learning and teaching can influence students' skills development have been highly under-researched, especially as the ever-increasing level of student engagement that has emerged from CETLs and other institutional initiatives produces results worth exploring. While all students involved in the study were able to pinpoint direct experiences taken from their involvement with the CETLs, further exploration is needed, preferably in discussion with students, to identify exactly how this aspect of skills development compares to skills gathered as part of the disciplinary degree programme. Long-term follow-ups could provide useful data informing the field on any impact extra-curricular activity has had on students engaged in CETLs.

The CETL programme came to an end in mid-2010 and, although it was not possible to sustain the ambassador and intern problems without CETL funding, the approaches which have been adopted at CILASS and CEEBL appear to have had a positive impact on student engagement and educational development practices in the two institutions 
concerned. At the University of Sheffield, there have been moves to establish departmental and faculty-level ambassador programmes to replace and build on the work done by the CILASS ambassadors, while at the University of Manchester, the intern programme has reaffirmed the institution's commitment to peer learning and student mentoring (for more on the long term impact of the networks see Wood et al.,2011).

\section{References}

Astin, A.W. (1999) 'Student involvement: a developmental theory for higher education', Journal of College Student Development, 40(5), pp. 518-529.

Atlay, M. and Harris, R. (2000) 'An institutional approach to developing students' 'transferable' skills', Innovations in Education and Teaching International, 37(1), pp. 76-84.

Bennett, R. (2002) 'Employers' demands for personal transferable skills in graduates: a content analysis of 1000 job advertisements and an associated empirical study', Journal of Vocational Education and Training, 54(4), pp. 457-476.

Brew, A. (2003) 'Teaching and research: new relationships and their implications for inquiry-based teaching and learning in higher education', Higher Education Research and Development, 22(1), pp. 3-18.

Bringle, R.G. and Hatcher, J.A. (1996) 'Implementing service learning in higher education', Journal of Higher Education, 67(2), pp. 221-239.

Bringle, R.G. and Hatcher, J.A. (2000) 'Institutionalization of service learning in higher education', Journal of Higher Education, 71(3), pp. 273-290.

Cohen, L., Manion, L. and Morrison, K. (2000) Research methods in education. 2nd edn. London: Routledge.

Cranmer, S. (2006) 'Enhancing graduate employability: best intentions and mixed outcomes', Studies in Higher Education, 32(2), pp. 169-184. 
Curtis S. and Shani, N. (2002) 'The effect of taking paid employment during term-time on students' academic studies', Journal of Further and Higher Education, 26(2), pp. 129-138.

Davies, L. (2000) 'Why kick the 'L' out of 'Learning'? The development of students' employability skills through part-time working', Education and Training, 42(8), pp. 436-444.

Eccles, J.S., Barber, B.L., Stone, M. and Hunt, J. (2003) 'Extracurricular activities and adolescent development', Journal of Social Issues, 59(4), pp. 865-889.

Feldman, A.F. and Matjasko, J.L. (2005) 'The role of school-based extracurricular activities in adolescent development: a comprehensive review and future directions', Review of Educational Research, 75(2), pp. 159-210.

Froman, L. (1999) 'The university as learning community', Journal of Adult Development, 6(3), pp. 185-191.

Gilman, R., Meyers, J. and Perez, L. (2003) 'Structured extracurricular activities among adolescents: findings and implications for school psychologists', Psychology in the Schools, 41(1), pp. 31-41.

Healy, M. (2005) 'Linking research and teaching to benefit student learning', Journal of Geography in Higher Education, 29(2), pp. 183-201.

Hutchings, B. (2007) Enquiry-based learning: definitions and rationale. Manchester: University of Manchester, Centre for Excellence in Enquiry-Based Learning. Available at: http://www.campus.manchester.ac.uk/ceebl/resources/papers/hutchings2007 defini ngebl.pdf (Accessed: 29 March 2011).

Kahn, P. and O'Rourke, K. (2004) Guide to curriculum design: enquiry-based learning. York: Higher Education Academy. Available at: http://www.campus.manchester.ac.uk/ceebl/resources/guides/kahn 2004.pdf (Accessed: 29 March 2011). 
Kirshner, B., O'Donoghue, J. and McLaughlin, M.W. (2005) 'Youth-adult research collaborations: bringing youth voice to the research process', in Mahoney, J.L., Larson, R. and Eccles, J.S. (eds.) Organized activities as contexts of development. Mahwah, New Jersey: Lawrence Erlbaum Associate, pp. 131-156.

Mathison, S. (1988) 'Why Triangulate?', Educational Researcher, 17(2), pp. 13-17.

Moran-Ellis, J., Alexander, V.D., Cronin, A., Dickinson, M., Fielding, J., Sleney, J. and Thomas, H. (2006) 'Triangulation and integration: processes, claims and implications', Qualitative Research, 6(1), pp. 45-59.

Muldoon, R. (2008) 'Recognising and rewarding the contribution and personal development of peer supporters at university', Journal of Further and Higher Education, 32(3), pp. 207-219.

Nabi, G.R. and Bagley, D. (1998) 'Graduates' perceptions of transferable personal skills and future career preparation in the UK', Career Development International, 3(1), pp. 31-39.

Powell, N., Moore, I., O'Rourke, K., Freeman, S., Sattenstall, M., Gough, G. and Jinks, P. (2007) 'Developing professional skills in three professional programmes through enquiry-based learning', in Carey, L., Huntley-Moore, S., Jordan, A., Magennis, S. and McMullin, B. (eds.) AISHE Conference 2007, Teaching and Learning in the Changing World of Higher Education, ed. 30th \& 31st August 2007, NUI Maynooth, Ireland. Dublin: All Ireland Society for Higher Education (AISHE). Available at: http://www.aishe.org/events/2006-2007/conf2007/proceedings/paper-27.doc (Accessed: 29 March 2011).

Schamber, L. (2000) 'Time-line interviews and inductive content analysis: their effectiveness for exploring cognitive behaviors', Journal of the American Society for Information Science and Technology, 51(3), pp. 734-744. 
Schraw, G., Crippen, K.J. and Hartley, K. (2006) 'Promoting self-regulation in science education: metacognition as part of a broader perspective on learning', Research in Science Education, 36(1-2), pp. 111-139.

The University of Sheffield (n.d.) The Sheffield Graduate Award. Available at: http://www.shef.ac.uk/thesheffieldgraduateaward/ (Accessed: 29 March 2011).

Wood, J., Goldring, L., Bestwick, A. and Barnes, E. (2011) 'A collaborative evaluation of student-staff partnership in inquiry-based educational development', in Little, S. (ed.) Staff-student partnership in higher education. London: Continuum, pp. 16-30.

Wood, J., Little, S., Goldring, L. and Jenkins, L. (2011) 'The confidence to do things that I know nothing about' - skills development through extra-curricular inquiry activity: a literature review. Available at: http://www.jiscmail.ac.uk/files/ldhen/WoodLitReview.pdf (Accessed: 29 March 2011)

\section{Author details}

Dr Jamie Wood is Leverhulme Early Career Postdoctoral Fellow in Religions and Theology at the University of Manchester. From 2007 to 2009 he was Learning Development and Research Associate at the Centre for Inquiry-based Learning in the Arts and Social Sciences at the University of Sheffield.

Dr Sabine Little was Learning Development and Research Associate at the Centre for Inquiry-based Learning in the Arts and Social Sciences at the University of Sheffield from 2005 to 2010.

Louise Goldring is Innovation and Development Advisor at the Royal College of Surgeons. From 2008 to 2010 she was Student Engagement Officer at the Centre for Excellence in Enquiry-Based Learning at the University of Manchester.

Laura Jenkins was coordinator of the Student Ambassador Network at the Centre for Inquiry-based Learning in the Arts and Social Sciences at the University of Sheffield from 2007 to 2008. 